\title{
The Price-Volume Relationship In The Chilean Stock Market
}

\author{
Ravindra R. Kamath, Cleveland State University, USA
}

\begin{abstract}
This study focuses on the econometric relations between daily returns and daily trading volume changes on the Santiago Stock Exchange of Chile. To meet this task, the study utilizes the data of the Selective Stock Price Index, IPSA, from January, 2003 through October, 2006. A significant contemporaneous relation is found between volume and returns. The evidence also indicates that the said relation is asymmetric. Moreover, the results support the notion that the trading volume makes the market move. The causality test results provide a clear evidence of daily returns Granger causing daily trading volume changes in the Chilean equity market.
\end{abstract}

Key words: Chile, Price-volume relationship, Asymmetric relationship

\section{INTRODUCTION}

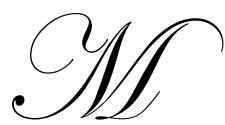

any different aspects of P-V relations have been investigated for speculative markets around the world for almost 60 years. By conducting a thorough survey of literature, Karpoff (1987) provided an excellent overview of the numerous issues surrounding this important topic. According to Karpoff, the primary reason for studying the P-V relations is that such studies can help our understanding of the underlying structure of any market.

Two of the most frequently studied P-V relations are linked to the well-publicized Wall Street adages. Market participants generally view the price increases accompanied by relatively high volume as an indicator of a bullish sentiment and price declines accompanied by relatively heavy volume is an indicator of a bearish sentiment. Another commonly quoted postulate views the trading volume as the generator of price movements (see Stickel and Verrecchia, 1994). Accordingly, numerous empirical investigations have focused on trying to ascertain support for these postulates primarily with the help of developed financial markets. Only a handful of published studies of P-V relations in the developing markets can be found. This paucity is one the motivating factor for the present study.

The primary objective of this study is to investigate econometric relations between stock market returns and trading volume on the Santiago Stock Exchange of Chile. To fulfill this objective, the study utilizes the daily data of the Selective Stock Price Index, IPSA (Indice de Precios Selectivo de Acciones) over the recent 46-month period ending in October, 2006. The specific goals of this study are:

1. To ascertain if the rising markets are accompanied by rising volume and vice versa;

2. To ascertain if the empirical evidence of the IPSA indicates an asymmetric P-V relationship with respect to the direction of the market;

3. To ascertain if the trading volume is needed to bring about the market movements; and

4. To ascertain the existence of and the direction of the Granger causality between returns and volume.

The relevant literature is briefly covered in the next section. The data, the variables and the methodologies utilized in this study are described in the following section. The findings of the study are presented in the fourth section. A summery of the paper is in the final section. 


\section{LITERATURE REVIEW}

The body of noteworthy literature on P-V relations is sizable. Empirical research has often led to conflicting conclusions depending on the data utilized, the time period studied and the underlying markets. Karpoff's reviews (1987) of the pioneering studies of the P-V relations and a synthesis of the findings have provided considerable impetus for conducting empirical research. Many of the P-V relation studies from the last 15 years are founded on the influential works of Ying (1966), Crouch (1970), Clark (1973), Copeland (1974), Epps and Epps (1976), Westerfield (1977), Rogalski (1978) and Smirlock and Starks (1988).A positive correlation between absolute values of returns and trading volume were reported by Crouch (1970) for market indices as well as individual stocks. A similar finding was also reported by Wood, et. al (1985) for the transactions data of NYSE stocks. A positive correlation between price changes and volume has been reported by Westerfield (1977) and Rogalski (1978), among others. Chen, et. al (2001) have elaborated on the four models emerging from the P-V relation studies, namely, the SAI model (sequential arrival of information), the MD model (mixture of distributions), the REAP model (rational expectation asset pricing), and the DO model (differences of opinion).

The Granger causality method (Granger, 1969) has been adopted by many studies including those by Rogalski (1978), Jain and Joh (1988), Martikainen, et. al (1994), Hiemstra and Jones (1995), Saatcioglu and Starks (1998), Chen, et. al (2001), and Kamath and Wang (2006), among others to ascertain the presence of causality between return and volume. The study of the Finnish stock market by Martikainen, et. al (1994) found a bidirectional feedback between stock returns and volume. Chen, et. al (2001) investigated the P-V relation in nine developed equity markets and found evidence of a positive correlation between volume and the absolute value of returns. They also found returns Granger causing volume and to a much smaller extent, volumes Granger causing returns. They reported a significant bi-directional feedback for the markets of Hong Kong, the Netherlands and Switzerland. Jain and Joh (1988) examined the hourly returns and volume on the NYSE reported a significantly positive correlation between volume and absolute returns though they noted differences in this relation for positive and negative returns.

Saatcioglu and Starks (1998) studied six Latin American equity markets with at least $\$ 5$ billion in market capitalization including the Chilean market over the 1986-1995 period with the help of monthly data. They reported significant positive correlations between volume and price changes as well as the magnitude of price changes. In the markets of Brazil, Columbia, Mexico and Venezuela, they found evidence of volume Granger causing returns. Aggarwal, et. al (1999) who studied volatility in emerging markets did utilize the Chilean stock market data but relied on an alternative index known as the IGPA. Kamath and Wang (2006) examined the P-V relation in six Asian equity markets over the January 2003 to October 2005 period. They provided support for the notion that trading volume induces price movements in five of the six markets they studied. Moreover, they presented an evidence of significantly positive relation between volume and returns even though this relation was found to be asymmetric with respect to the market direction. The findings of the Granger causality tests indicated an absence of causality in either direction in four of the six markets. They reported evidence of causality running from returns to volume in the South Korean market and a diametrically opposite direction of causality in the Taiwanese market.

\section{DATA AND METHODOLOGY}

To meet the four-fold objective of this study, the daily data of the IPSA, the index of the Santiago Stock Exchange of Chile were utilized. The daily closing index prices and the daily trading volume of the IPSA were used from January, 2003 to October, 2006 giving rise to 956 pairs of the relevant data. The IPSA is a value weighted index composed of the 40 most actively traded stocks and this composition is revised quarterly. This index has been computed since 1977. The Santiago Stock Exchange operates Monday through Friday except for public holidays.

From the raw data of the closing index values and the trading volume in the local currency, namely in Chilean Pesos (CLP), the daily rates of return (R), the absolute values of returns (AR) and the volume measures (V) were computed using the following three equations.

$$
R=\left(\left(P_{t} / P_{t-1}\right)-1\right) \times 100
$$




$$
V=\left(\left(V_{t} / V_{t-1}\right)-1\right) \times 100
$$

$$
A R=\text { Absolutevalue of } R
$$

In these equations, $P_{t}$ and $V_{t}$ stand for closing index price on day $t$ and the trading volume on day $t$, respectively. As equation (2) indicates, the volume variable computation in this paper is identical to the return computation. Thus, both $\mathrm{R}$ and $\mathrm{V}$ are $\%$ change functions and therefore, both measures can take on positive as well as negative values. Different formulations of volume as well as return can be found in the literature on the topic at hand. For example, while Jain and Joh (1988) relied on the raw values of trading volume, Martikainen, et. al (1994) and Chen and Zhou (2001) utilized natural logarithm of raw volume figures. The Saatcioglu and Starks study (1998) of Latin American markets adopted the ratio of raw volume to the market capitalization as their volume measure. One common aspect of these different volume measures is that they lead to performing regressions in which returns can assume positive as well as negative values but volume can assume only positive values. This methodological setback is overcome with the definition of the volume measure in this study as was the case in the Kamath and Wang study (2006) while still retaining the essence of the properties needed to test the main postulates of the P-V relations.

The paper first attempts to determine if the evidence supports the notion that the rising markets tend to be accompanied by rising volume and the falling markets tend to be accompanied by falling volume. Equation (4) is utilized to determine if the estimated coefficient, B, for the IPSA is positive and statistically significant.

$$
V=A+B(R)
$$

The second goal of the paper attempts to determine if the P-V relation is "fundamentally different" for the diametrically opposite market directions as shown in Figure 1 of Karpoff (1987, p121). This goal is met by separately estimating equation (4) for the days when the IPSA made gains and for the days when it registered losses. The third objective of the paper is to determine if it takes volume to make the IPSA move. Basically, the testing will determine if large volume accompany large magnitudes of returns and vice versa. The testing will determine if the estimated coefficient D in equation (5) is significantly positive and for the IPSA as found in most stock markets.

$$
V=C+D(A R)
$$

In equations 4 and 5, the estimated constant terms are denoted by $\mathrm{A}$ and $\mathrm{C}$, and $\mathrm{B}$ and $\mathrm{D}$ are the estimated coefficients of independent variables, returns and absolute returns, respectively.

Equations 4 and 5 ascertain the contemporaneous relations between returns and volume changes. For example, if the estimated coefficient $\mathrm{D}$ of absolute returns is significantly positive, it would indicate that volume contemporaneously cause returns. The fourth objective of the paper is to determine existence of and the direction of causality between returns and volume on the IPSA using the Granger causality methodology (Granger, 1969). As per this method, the test attempts to ascertain if the changes in the first variable, such as the returns, cause the second variable, such as the volume, to change even when controlled for the past changes in the second variable (volume). The null hypotheses tested in this study are stated by equations (6) and (7). In this study, lags of up to 5 business days are used for estimating Granger Causality as described by complete equations (8) and (9).

\section{$R$ doesnot Granger cause $V$}

$V$ does not Granger cause $R$

$V_{t}=G_{0}+\sum_{i=1}^{5} G_{i} V_{t-i}+\sum_{j=1}^{5} H_{j} R_{t-j}$

$R_{t}=S_{0}+\sum_{i=1}^{5} S_{i} R_{t-i}+\sum_{j=1}^{5} Q_{j} V_{t-j}$ 
With the help of equation (9), if the estimated coefficients $Q_{j}$ are found to be statistically significant, it would lead to a conclusion that returns are Granger caused by volumes on the IPSA. Specifically, it would indicate that the prediction of future daily returns would be improved if the independent variables include the past 5 values of daily returns along with the past 5 values of daily volumes rather than just the past 5 values of daily returns. On the other hand, if the F-test fails to reject the hypothesis that $\mathrm{Q}_{1}, \mathrm{Q}_{2}, \mathrm{Q}_{3}, \mathrm{Q}_{4}, \mathrm{Q}_{5}=0$, the conclusion would be that volumes do not Granger cause returns. Similarly if the F-test fails to reject the hypothesis that $\mathrm{H}_{1}, \mathrm{H}_{2}, \mathrm{H}_{3}, \mathrm{H}_{4}, \mathrm{H}_{5}=0$, the conclusion would be that returns do not Granger cause volumes.

\section{FINDINGS}

The raw data of the IPSA closing prices and the trading volume are summarized in Table 1. The Santiago Stock Exchange index, IPSA, began the year 2003 just above 1008. As the table shows, IPSA gained every year of the study and over the 46 month period it registered a gain of about 237 percent. Concurrently, the average trading volume of the IPSA stocks also grew steadily. Table 1 also shows the high disparity between the lowest and the highest daily volume in the market under study.

The statistical properties of the daily rates of return and the trading volume $\%$ changes on the IPSA are summarized in Table 2. Over the study period, the mean as well as the median returns were positive. The measure of risk per unit of return, namely, the coefficient of variation of daily returns, can be computed to be 10.37 on the IPSA. For a somewhat comparable period, Kamath and Wang (2006) have reported the coefficient of variation values of 14.66. 12.33. 11.79, 14.92, 29.58 and 8.60 for the markets of Hong Kong, Malaysia, Singapore, South Korea, Taiwan and Indonesia, respectively. For the overall period, the Table 2 exhibits a negatively skewed return distribution of the IPSA. This finding is similar to that found for all 9 developed markets studied by Chen, et. al (2001) as well as for 4 of the 6 Asian markets reported by Kamath and Wang (2006). For the study period, Table 2 shows Kurtosis of the return distribution to be far in excess of 3.0, as has been reported for the developed as well as the developing markets around the world. Thus, the evidence clearly points to a peaked and fat tailed return distribution for the IPSA. The statistical distribution of the volume variable of the IPSA is described by large standard deviations, a positive skew and a large kurtosis. These characteristics of volume on the Chilean market are very much comparable to those reported by Kamath and Wang (2006) for the six Asian Markets. Since this paper tests for the asymmetric relation between returns and volume, the overall data is divided into two sets. Out of the 956 total market days in this study, the IPSA went up on 530 days and lost ground on 426 days. The statistical attributes of distributions in the two sets in Table 2 are largely similar.

Table 1

Raw Data on the Daily Volume Measured in Chilean Peso and the Closing Prices on the IPSA of Santiago Stock Exchange of Chile, 1/2003 - 10/2006

\begin{tabular}{|l|c|c|c|c|}
\hline Period & $1 / 1 / 2003-$ & $1 / 1 / 2004-$ & $1 / 1 / 2005-$ & $1 / 1 / 2006-$ \\
\hline Highest Index Close & $12 / 31 / 2003$ & $12 / 31 / 2004$ & $12 / 31 / 2005$ & $10 / 25 / 2006$ \\
Date & $1,585.78$ & $1,825.34$ & $2,214.07$ & $2,386.44$ \\
\hline Lowest Index Close & $10 / 21 / 2003$ & $12 / 22 / 2004$ & $08 / 02 / 2005$ & $10 / 25 / 2006$ \\
Date & 982.17 & $1,390.63$ & $1,710.07$ & $1,939.60$ \\
\hline Last Day Index Close & $01 / 27 / 2003$ & $05 / 10 / 2004$ & $01 / 12 / 2005$ & $01 / 02 / 2006$ \\
\hline $\begin{array}{l}\text { Highest Volume(million CLP) } \\
\text { Date }\end{array}$ & $1,484.80$ & $1,796.48$ & $1,964.47$ & $2,386.44$ \\
\hline $\begin{array}{l}\text { Lowest Volume(million CLP) } \\
\text { Date }\end{array}$ & $165,755.68$ & $241,300.28$ & $230,254.17$ & $356,630.44$ \\
\hline $\begin{array}{l}\text { Average Daily Volume } \\
\text { (million CLP) }\end{array}$ & $11 / 19 / 2003$ & $11 / 12 / 2004$ & $07 / 14 / 2005$ & $03 / 24 / 2006$ \\
\hline & $02 / 03 / 2003$ & $5,727.08$ & $9,037.03$ & $9,922.96$ \\
\hline & $18,049.68$ & $28,964.46$ & $41,554.45$ & $01 / 16 / 2006$ \\
\hline
\end{tabular}


Table 2

Statistical Attributes of Daily Returns and Trading Volume Changes on the Santiago Stock Exchange of Chile, 1/2003 - 10/2006

\begin{tabular}{|c|c|c|c|c|c|c|}
\hline Which days & \multicolumn{2}{|c|}{ All market days } & \multicolumn{2}{c|}{$\begin{array}{c}\text { The days when the market } \\
\text { went up }\end{array}$} & \multicolumn{2}{c|}{$\begin{array}{c}\text { The days when the market } \\
\text { went down }\end{array}$} \\
\hline Variable & Return \% & Volume \% & Return \% & Volume \% & Return \% & Volume \% \\
\hline Mean & 0.093 & 19.518 & 0.644 & 23.228 & -0.592 & 14.912 \\
\hline Median & 0.092 & -1.359 & 0.556 & 7.313 & -0.465 & -8.709 \\
\hline Maximum & 2.882 & 1742.6 & 2.882 & 627.03 & -0.0005 & 1742.6 \\
\hline Minimum & -4.371 & -89.72 & 0.0001 & -88.90 & -4.371 & -89.72 \\
\hline Std. Dev. & 0.80 & 101.95 & 0.51 & 77.62 & 0.52 & 125.78 \\
\hline Skewness & -0.21 & 7.72 & 1.17 & 2.94 & -1.92 & 8.45 \\
\hline Kurtosis & 4.34 & 105.20 & 4.46 & 17.44 & 10.51 & 100.18 \\
\hline Jarque-Bera & 78.5 & 9999.9 & 168.3 & 5370.4 & 1262.5 & 9999.9 \\
\hline Observations & 956 & 956 & 530 & 530 & 426 & 426 \\
\hline
\end{tabular}

Table 3

Contemporaneous Relationship between Volume and Return on the IPSA, 1/2003 - 10/2006

\begin{tabular}{|c|c|c|c|c|c|c|}
\hline \multirow{3}{*}{$\begin{array}{c}\text { Which days } \\
\text { Variable }\end{array}$} & \multicolumn{6}{|c|}{ Equation $4 \quad V=A+B(R)$} \\
\hline & \multicolumn{2}{|c|}{ All market days } & \multicolumn{2}{|c|}{$\begin{array}{l}\text { The days when the market } \\
\text { went up }\end{array}$} & \multicolumn{2}{|c|}{$\begin{array}{l}\text { The days when the market } \\
\text { went down }\end{array}$} \\
\hline & $\mathrm{A}$ & $\mathrm{B}$ & $\mathrm{A}$ & $\mathrm{B}$ & $\mathrm{A}$ & $\mathrm{B}$ \\
\hline Coefficient & 18.65 & 9.27 & 5.12 & 28.12 & 12.11 & -4.72 \\
\hline t-statistic & 5.63 & 2.25 & 0.95 & 4.28 & 1.32 & 0.41 \\
\hline Probability & 0.0000 & 0.0244 & 0.3415 & 0.0000 & 0.1892 & 0.6859 \\
\hline Adjusted R-square & \multicolumn{2}{|c|}{0.004} & \multicolumn{2}{|c|}{0.032} & \multicolumn{2}{|c|}{-0.002} \\
\hline F-Statistic & \multicolumn{2}{|c|}{5.08} & \multicolumn{2}{|c|}{18.29} & \multicolumn{2}{|c|}{0.16} \\
\hline
\end{tabular}

Table 4

Contemporaneous Relationship between Volume and Absolute Return on the IPSA, 1/2003 - 10/2006

\begin{tabular}{|c|c|c|}
\hline \multicolumn{1}{|c|}{ Equation 5 } & V= C + D (AR) & D \\
\hline Variable & C & 17.63 \\
\hline Coefficient & 8.57 & 2.76 \\
\hline t-statistic & 1.66 & 0.0059 \\
\hline Probability & 0.0966 & \multicolumn{2}{|c|}{7.007} \\
\hline Adjusted R-square & \multicolumn{2}{|c|}{} \\
\hline F-Statistic & \multicolumn{2}{|c|}{} \\
\hline
\end{tabular}

Table 3 contains the findings regarding the contemporaneous relation between volume and return for the overall period using equation (4). The results indicate a significantly positive relation between volume and returns and thereby suggest that rising markets are accompanied by rising volume and vice versa. This evidence on IPSA is comparable to the evidence reported for many of the developed as well as developing markets. Table 3 also contains the equation (4) estimations separately for the up and the down market days. Karpoff (1987) had reasoned that the correlation between volume and positive (negative) price changes is likely to be positive (negative). While the tabulated findings of IPSA indicate a weak asymmetric relationship, it is statistically significant only for the rising market. In this respect the findings of IPSA are not as robust as the reported evidence for the Asian Equity Markets.

The estimations of the contemporaneous relations between daily volume and the absolute values of the daily returns are presented in Table 4. The evidence of a significantly positive correlation between volume and the magnitudes of the daily returns strongly suggest that trading volume changes bring about the stock market 
movements on the Santiago stock exchange. In this respect, the observed evidence on the IPSA is in agreement with the evidence reported by Chen, et. al (2001) for nine developed markets, by Kamath and Wang (2006) for the developing Asian markets and for four of the six developing markets from the Latin America by Saatcioglu and Starks (1998) including for Chile during the 1986-1995 period.

In a contemporaneous setting, the IPSA results show that daily returns cause trading volume changes (Table 3) and daily trading volume changes cause stock prices movements (Table 4). Accordingly, we now turn our attention to ascertaining if there is evidence of Granger causality between daily returns and trading volume changes on the IPSA. In this study lags of up to 5 market days are considered in testing for the Granger causality hypotheses. Thus, the right hand sides of equations (8) and (9) require estimating 11 coefficients. Instead of providing all 11 estimated coefficients and the associated t-values, only the resulting F-statistics are exhibited in Table 5. This investigation finds evidence of significant Granger causality running from returns to volume. The Granger causality findings of Saatcioglu and Starks (1998) for Chile were somewhat comparable. The evidence uncovered in this study, namely, that of significant Granger causality running only from returns to volume on the IPSA is comparable to that reported for many of the developed markets such as the markets of U.S, Japan, UK, France and Italy.

Table 5

A Summary of Granger Causality Test Results, Santiago Stock Exchange of Chile, 1/2003-10/2006

\begin{tabular}{|c|c|c|}
\hline Null Hypothesis & $\begin{array}{c}\text { Return Does Not Granger Cause } \\
\text { Trading Volume }\end{array}$ & $\begin{array}{c}\text { Trading Volume Does Not Granger } \\
\text { Cause Return }\end{array}$ \\
\hline F-Statistic & 3.889 & 0.2803 \\
\hline Probability & 0.0017 & 0.9240 \\
\hline
\end{tabular}

\section{SUMMARY}

This paper has reported the empirical findings of an investigation of econometric relations between daily returns and the trading volume changes on IPSA, the index of the Santiago Stock Exchange of Chile. More than 950 pairs of return-volume data from January 2003 to October 2006 were used to meet the task at hand. During the 46 month study period, the IPSA gained almost 240 percent.

The study indicated that the IPSA's rise was accompanied by a rising volume and the IPSA's fall was accompanied by a falling volume. This relationship was found to be asymmetric with respect to the market direction itself though not in a statistically significant fashion. The contemporaneous relation between the volume and the magnitudes of returns was found to be significantly positive and thereby suggesting that trading volume changes were instrumental in bringing about the index movements. Moreover, the evidence pointed out that a significant Granger causality was present on the IPSA and it ran only from returns to volume.

\section{AUTHOR INFORMATION}

Ravindra Kamath is Professor of Finance at Cleveland State University. He conducts research in the areas of Financial Education, Investments and Corporate Finance. His research has been published in Financial Review, Financial Management, Journal of Portfolio Management, Journal of Applied Finance, Journal of Economics and Finance Education, Asia Pacific Journal of Accounting and Economics and Journal of Economics and Finance, among others.

\section{REFERENCES}

1. Aggarwal, R., C. Inclan and R. Leal, "Volatility in Emerging Stock Markets," Journal of Financial and Quantitative Analysis, Vol. 34, 1999, 33-55.

2. Chen, G., M. Firth, and O. Rui, "The Dynamic Relation between Stock Returns, Trading Volume and Volatility," The Financial Review, Vol.38, 2001, 153-174. 
3. Chen, C. and Z. Zhou, "Stock Returns, Volatility, and Trading Volume: Evidence from the Chinese Stock Markets," International Journal of Business, Vol. 6, No.2, 2001, 67-86

4. Clark, P., "A Subordinated Stochastic Process Model with Finite Variance for Speculative Prices," Copeland, T.E., "A Model of Asset Trading Under the Assumption of Sequential Information Arrival," Journal of Finance, Vol.31, 1976, 1149-1168.

5. Crouch, R., "The Volume of Transactions and Price Changes on the New York Stock Exchange," Financial Analysis Journal, Vol. 26, 1970, 104-109.

6. Epps, T. and M. Epps, "The Stochastic Dependence of Security Price Changes and Transaction Volumes: Implications for the Mixture-of-Distributions Hypothesis," Econometrica, Vol. 44, 1976, 305-321.

7. Granger, C., "Investigating Causal Relations by Econometric Models and Cross-Spectral Methods," Econometrica, Vol. 37, 1969, 424-438.

8. Hiemstra, C. and J. Jones, "Testing for Linear and Nonlinear Granger Causality in the Stock Price-Volume Relation,” Journal of Finance, Vol. 49, 1994, 1639-1664.

9. Jain, P. and G. Joh, "The Dependence between Hourly Prices and Trading Volume," Journal of Financial and Quantitative Analysis, Vol.23, 1988, 269-283.

10. Kamath R. and Y. Wang, "The Causality between Stock Index Returns and Volumes in the Asian Equity Markets," Journal of International Business Research, Vol.5, 2006, 63-74.

11. Karpoff, J., "The Relation Between Price Changes and Trading Volume: A Survey," Journal of Financial and Quantitative Analysis, Vol. 22, 1987, 109-126.

12. Martikainen, T., V. Puttonen, M. Luoma, and T. Rothovius, "The Linear and Non-Linear Dependence of Stock Returns and Trading Volume in the Finish Stock Market," Applied Financial Economics, Vol. 4, 1994, 159-169.

13. Rogalski, R., "The Dependence of Prices and Volume," Review of Economics and Statistics, Vol. 60, 1978,

14. Saatcioglu, K. and L. Starks, "The Stock Price-Volume Relationship in Emerging Stock Markets: The Case of Latin America," International Journal of Forecasting, Vol. 14, 1998, 215-225.

15. Smirlock, M. and L. Starks, "An Empirical Analysis of the Stock Price-Volume Relationship," Journal of Banking and Finance, Vol. 12, 1988, 31-41.

16. Stickel, S. and R. Verrecchia, "Evidence that Trading Volume Sustains Stock Price Changes," Financial Analysts Journal, November-December, 1994, 57-67.

17. Westerfield, R., "The Distribution of Common Stock Price Changes: An Application of Transactions Time and Subordinated Stochastic Models," Journal of Financial and Quantitative Analysis, Vol. 12, 1977. 743 765 .

18. Wood, R., T. McInish and J. Ord, “An Investigation of Transactions Data for NYSE Stocks," Journal of Finance, Vol.60, 1985, 723-739.

19. Ying, C., "Stock Market Prices and Volumes of Sales," Econometrica, Vol. 34, 1966, 676-685. 


\section{NOTES}

